

Pedro Henrique Rosado de Castro

Seleção Adversa e Concorrência no Mercado de Crédito para Pessoa Física no Brasil

Dissertação apresentada como requisito parcial para obtenção do título de Mestre pelo Programa de Pós-Graduação em Economia da PUC-Rio.

Orientador: João Manoel Pinho de Mello

Rio de Janeiro

Março de 2008 


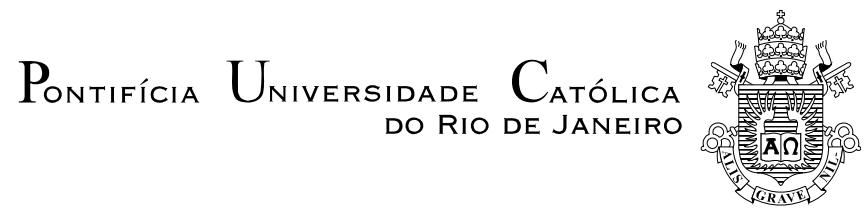

Pedro Henrique Rosado de Castro

\section{Seleção Adversa e Concorrência no Mercado de Crédito para Pessoa Física no Brasil}

João Manoel Pinho de Mello Orientador PUC - Rio

Leonardo Rezende PUC - Rio

Cláudio Ferraz IPEA e PUC - Rio

Prof. Nizar Messari Coordenador(a) Setorial do Centro de Ciências Sociais - PUC-Rio 
Todos os direitos reservados. É proibida a reprodução total ou parcial do trabalho sem autorização da universidade, do autor e do orientador.

\section{Pedro Henrique Rosado de Castro}

Graduado em economia pela Universidade Estadual de Campinas (UNICAMP) em 2004. Cursou entre 2006 e 2007 o mestrado em economia da PUC-Rio.

Ficha Catalográfica

Castro, Pedro Henrique Rosado

Seleção adversa e concorrência no mercado de crédito para pessoa física no Brasil / Pedro Henrique Rosado de Castro; orientador: João Manoel Pinho de Mello - Rio de Janeiro: PUC-Rio. Departamento de Economia. 2008

$82 f . ; 30 \mathrm{~cm}$

Dissertação (Mestrado em Economia) - Pontifícia Universidade Católica do Rio de Janeiro, Rio de Janeiro, 2008

Incluí referências bibliográficas.

1. Economia - Teses. 2. Microeconomia bancária, 3. Pass-through, 4. Seleção Adversa. I. Mello, João Manoel Pinho de. II. Pontifícia Universidade Católica do Rio de Janeiro. Departamento de Economia. III. Título 


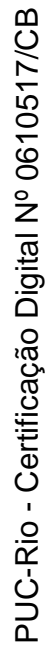

Ao meu avô, José Ribeiro da Silva (in memoriam) 


\section{Agradecimentos}

A CAPES pelo apoio financeiro para a realização do Mestrado.

Ao meu orientador, João Manoel Pinho de Mello pela atenção e total disposição para sempre discutir os desenvolvimentos do artigo. E pelas inúmeras conversas sobre os mais variados assuntos.

Aos membros da banca examinadora, professores Leonardo Rezende e Cláudio Ferraz, pelas criticas e sugestões.

Aos meus colegas de classe que propiciaram um ambiente intelectualmente muito estimulante e desafiador para a realização de um mestrado.

Aos professores e funcionários do departamento de economia da PUC-Rio pela dedicação que permite a PUC-Rio manter uma posição de destaque tanto na pesquisa quanto no debate sobre política econômica no Brasil.

Ao meu avô José Ribeiro da Silva (in memoriam). Sem ele nada seria possível. Retornar ao Rio e poder usufruir de sua companhia nos almoços e caminhadas semanais já faria valer em si o esforço de realizar essa tese.

À minha família, pelo apoio e amor incondicional nessa volta ao Rio de Janeiro. À minha mãe, super mãe, que me acolheu e sempre me incentivou. Ao Raul pela paciência e exemplo de vida, e ao meu irmão Paulinho, que apesar das pequenas diferenças é e sempre será meu melhor amigo.

À Andrea Santichio. Jamais imaginaria que a prova da Anpec me permitiria conhecer e conviver com aquela que seria a mulher da minha vida. 


\section{Resumo}

Castro, Pedro Henrique; Mello, João Manoel Pinho de (Orientador). Seleção Adversa e Concorrência no Mercado de Crédito para Pessoa Física no Brasil. Rio de Janeiro, 2008. 82p. Dissertação de Mestrado Departamento de Economia, Pontifícia Universidade Católica do Rio de Janeiro.

Este trabalho testa e encontra evidência de que as taxas de juros de empréstimos bancários respondem mais a aumentos do que a quedas na taxa básica de juros (Selic). A assimetria sobrevive a uma análise de evento, na qual a disponibilidade de uma base com dados diários é explorada com o objetivo de isolar o choque de política monetária sobre os juros. Dentre as potencias teorias que racionalizam essa assimetria, duas são consideradas. A primeira refere-se à existência de poder de mercado, o que permite aos bancos coordenarem um menor repasse como forma de aumentar os lucros de curto prazo. A segunda argumenta que a presença de forte seleção adversa no mercado de crédito diminui o incentivo à concorrência na dimensão preço, reduzindo o repasse de quedas no custo de captação. Como as duas hipóteses produzem implicações empíricas similares em forma reduzida, o artigo propõe e estima um modelo estrutural a fim de testar qual dos dois modelos melhor se ajusta aos preços e quantidades observados no mercado de crédito para pessoa física.

\section{Palavras-chave}

Micro Economia Bancária, pass-through e Seleção Adversa. 


\section{Abstract}

Castro, Pedro Henrique; Mello, João Manoel Pinho de (Orientador). Adverse Selection and Competition in the Market for Household Credit in Brazil. Rio de Janeiro, 2008. 82p. M.A. Dissertation Departamento de Economia, Pontifícia Universidade Católica do Rio de Janeiro.

This paper tests and find evidence that support the view that credit interest rates respond more to increases than to decreases in the Central Bank basic interest rate (Selic). This asymmetry is robust to an event analysis, in which the availability of a dataset containing daily information is explored in order to isolate monetary policy shocks on interest rates. Among the possible explanations for this asymmetry, two are considered in the article. The first one refers to the existence of market power, which allows banks to coordinate on a smaller pass-through in order to increase profits in the short run. The second refers to the potential existence of severe adverse selection issues in the credit market, which diminishes the incentives to compete on the interest rate dimension and consequently the pass-through from decreases in the cost of funds. Since the two theories present similar empirical implications in reduced forma analysis, the article proposes and estimates a structural model in order to test which of the competing theories better fits the observed data on prices and quantities for household credit in Brazil.

\section{Keywords}

Microeconomics of Banking, interest pass-through and Adverse Selection 


\section{Sumário}

1 Introdução

2 Descrição dos Dados 17

2.1. Evolução Recente do Mercado de Crédito Brasileiro 17

2.2. Base de Dados 19

2.3. Estatísticas Descritivas 21

3 A Resposta dos Juros Bancários a Variações na Selic é Assimétrica? 25

3.1. Análise de Forma Reduzida: Motivação Teórica 25

3.2. Análise em Séries de Tempo 29

3.2.1. Modelo Empírico $\quad 29$

3.2.2. Resultados 32

3.2.3. Robustez: Incluindo termo AR na equação de Mark-up 35

3.3. Análise de Evento 37

3.3.1. Metodologia 37

3.3.2. Resultados 38

4 Estimação Estrutural $\quad 41$

4.1. Dificuldades Práticas da Estimação e da Interpretação dos

Resultados em Forma Reduzida 41

4.2. O Modelo 44

4.2.1. O Lado da Demanda 44

4.2.2. Oferta: Bertrand-Nash com Seleção Adversa 47

4.2.3. Oferta: A solução de Cartel 51

4.3. Modelo Empírico: Hipóteses sobre a função Verossimilhança 52

5 Resultados da Estimação Estrutural 56

5.1. Demanda: estimativa das Elasticidades 56

5.2. Oferta: Parâmetros Estimados 59

5.3. Comparando as hipóteses de Bertrand Nash versus Cartel 63 
6 Conclusão

69

7 Bibliografia

71

8 Apêndice 


\section{Lista de ilustrações}

Ilustração 1: Evolução do Crédito. Total, Direcionado e Livre e Crédito Livre por Destinatário

Ilustração 2: Evolução dos Juros Diários e Meta Selic

Anualizada - Cheque Especial e CDC

Ilustração 3: Evolução dos Juros Diários e Meta Selic

Anualizada - Automóveis, Bens Outros e Cartão de Crédito

77

Ilustração 4: Margem Preço Custo por Modalidade

82 


\section{Lista de tabelas}

Tabela 1: Correlações entre juros e Selic, freqüência mensal e diária 23

Tabela 2: Teste de Assimetria, séries de tempo 33

Tabela 3: Teste Assimetria, séries de tempo por Modalidade 34

Tabela 4: Análise de Evento OLS por modalidade. Janela 2 dias 39

Tabela 6: Modelo de Bertrand-Nash, Parâmetros da

$\begin{array}{ll}\text { Estimação Estrutural } & 60\end{array}$

Tabela 7: Modelo Cartel, Parâmetros da Estimação Estrutural 61

De posse dessas informações a 65

Tabela 8: Teste de Vuong $\quad 65$

Tabela 9: Margem preço custo, Modelo I 67

Tabela 10: Margem preço-custo, Modelo III 68

Tabela 11: Freqüência dos dados: Modalidade e Segmento 74

Tabela 12: Estatísticas Descritivas, por modalidade e segmento 74

Ilustração 1: Evolução do Crédito. Total, Direcionado e Livre e Crédito $\begin{array}{ll}\text { Livre por Destinatário } & 76\end{array}$

Ilustração 2: Evolução dos Juros Diários e Meta Selic Anualizada Cheque Especial e CDC 76

Ilustração 3: Evolução dos Juros Diários e Meta Selic Anualizada Automóveis, Bens Outros e Cartão de Crédito 77

Tabela 15: Índices de Concentração por Modalidade de Crédito 79

Tabela 16: Painel com efeitos fixos e taxas de juros defasadas como $\begin{array}{ll}\text { variável explicativa } & 79\end{array}$

Tabela 17: Análise de Evento Cheque Especial 80

Tabela 18: Análise de Evento Cartão 80

Tabela 19: Análise de Evento Crédito Direto ao Consumidor 80

Tabela 20: Estimativa das Elasticidades da demanda 81

Tabela 21: Hipóteses para o vetor de chute inicial 81

Tabela 22: Intuindo o impacto do efeito seleção sobre as estimativas de Cmg 